\title{
Use of standards for CAD layers in building
}

\author{
Rob Howard, Bo-Christer Björk \\ Construction Communications, 8 Cotton's Field, Dry Drayton, Cambridge CB3 8DG, UK \\ Hanken, the Swedish School of Economics and Business Administration, \\ Arkadiankatu 22, PO Box 479, 00101 Helsinki, Finland
}

This is a so-called personal version (author's manuscript as accepted for publishing after the review process but prior to final layout and copyediting) of the article

Howard, Rob and Björk, Bo-Christer: 2007 Use of standards for CAD layers in building, Automation in Construction, Vol 16, pp. 290-297

Readers are kindly asked to use the official publication in references.

\begin{abstract}
One of the central issues in making efficient use of IT in the design, construction and maintenance of buildings is the sharing of the digital building data across disciplines and lifecycle stages. One technology which enables data sharing is CAD layering, which to be of real use requires the definition of standards. This paper focuses on the background, objectives and effectiveness of the International standard ISO 13567, Organisation and naming of layers for CAD. In particular the efficiency and effectiveness of the standardisation and standard implementation process are in focus, rather than the technical details. The study was conducted as a qualitative study with a number of experts who responded to a semi-structured mail questionnaire, supplemented by personal interviews. The main results were that CAD layer standards based on the ISO standard have been implemented, particularly in northern European countries, but are not very widely used. A major problem which was identified was the lack of resources for marketing and implementing the standard as national variations, once it had been formally accepted.
\end{abstract}

Key words: CAD, layers, standard, ISO

\section{Introduction}

The widespread use of IT in industry and society today is to a large degree enabled by a huge number of standards, few of which are known to end users. There are numerous standards related to hardware, software, computer networks 
and the Internet. Many of these have been developed as official standards by standardisation bodies; others have evolved through de-facto standardisation. In addition to such general purpose standards different industries have developed standards, both formal and de facto, for their particular data sharing needs.

In standardisation related to the use of IT application in construction, one of the central issues has been how to structure digital information about a building, to facilitate the sharing of data between the different design and construction disciplines involved in a project, as well as the transfer of the data between life cycle stages. This has also been a priority in industry-led development work and experimental projects and has been the focus of both national and international standardisation work. There has also been extensive research on this issue (For overviews see [1] and [2]).

Standardisation in this area has been related to different generations of basic technologies. The basics of computer-aided draughting developed in the 1960s and later evolved into CAD systems, first run on expensive minicomputers, but since the early 1980s also on personal computers [3]. Within a decade the technology became established in day-to-day architectural and engineering practice. The most widely used technique for managing the complex information contained in larger drawings and CAD models is layering. This consists of assigning graphical drawing elements of the same type to invisible layers, which can be turned on and off, both on the screen and in paper printouts, to help the user to focus on only that which is essential to his work, hiding the rest of the information. In-house, CAD-system specific and even national guidelines for layer assignment proliferated during the 1980's and at the end of that decade the need for an international standard was recognised by ISO. The standard resulting from this work, ISO 13567, became an official standard in 1997 [4]. This was developed after a number of related national standards had already emerged, and tried to provide a flexible framework which could easily be integrated with national building classification tables.

Simultaneously with the rapid proliferation of CAD systems, researchers started to look into more advanced forms of digital building representation than 2-D graphics oriented CAD, to help interoperability between the different types of design, analysis and management software used in the construction process [5]. These efforts were inspired by developments in data bases and programming, in particular object-oriented technology. The term building product model has been used to describe this type of representation. In 1985-86, when product model standardisation began in the ISO STEP forum, the construction industry was one of the industries in focus. The tasks to be solved in STEP were highly complex, more like developing a technology than standardising aspects of it and developments were slow in the early 1990s, in particular directly concerning the 
construction sector. As a result a number of industrial CAD users started in 1994 a parallel independent effort to develop a working building product model standard more quickly. The organisation created was the International Alliance for Interoperability, and the first official version of the Industry Foundation Classes was released in 1999 and work is still going on to develop it [6].

Both these standards essentially aim to solve the same problem, but using technology of different functionality and in different maturity stages. CAD layering has been an accepted and widely used technique in industry for twenty years, whereas building product modelling is only now starting to emerge from the experimental stage into regular day-to-day usage.

A very valid question is how successful these two standards have been. A follow-up question is then, if the standards have not been as successful as originally intended, what the reasons are for this. It would be very useful for future efforts to be able to learn as much as possible from previous efforts. Although numerous academic papers have been written about the development of the IFCs (for example [7], [8]), most of these have focused on the technical aspects of this highly complex standard and have often described proposed features of the standards and/or prototype work to test such features. Relatively little has been written about the ISO CAD layer standard [9], [10]. The authors have not found any papers studying these two standards from a standardisation efficiency perspective.

This paper focuses on the first of these standards, the ISO CAD layer standard 13567 (Technical product documentation - organisation and naming of layers for CAD) and tries to collect experiences from its definition, marketing and implementation in order to inform future standardisation activities.

\section{Methodology}

Despite the tremendous importance of standardisation in everyday life, particularly in IT applications, the study of how standards are defined and emerge and how they are applied has received relatively little attention in the scientific literature [11]. One possible reason might be that there is no one scientific discipline, which can explain standardisation as a phenomenon, since its study requires concepts and methods from various scientific disciplines [12].

Different research methodologies could be used for studying standardisation but, due to the widely differing scope and background of standardisation efforts, using quantitative techniques and broad surveys appears difficult and there are few reports of such studies. Case studies of individual standardisation efforts are, on the other hand, rather common and a lot of what researchers know or 
suggest as plausible generalisations comes from studies of individual cases [13]. Another type of research could be microeconomic game theory which could be used to simulate the behaviour of companies involved in standardisation activities that affect their competitiveness [14].

In this study the chosen method was the case study. The purpose was not so much to try to generalize to IT-standardisation in general as to offer useful insights for those interested particularly in the area of construction IT. Based on a literature review and the previous knowledge of the researchers ${ }^{1}$, aspects which are of particular interest were identified:

- The relation in time of the standardisation process to the maturing of the technology and its introduction in practice (anticipatory vs. postdeployment standardization).

- The technical complexity of the standard and what this has meant in terms of time and manpower needed for the committee decision making process.

- The marketing and support of the standard after it has been defined

- The relationship of the leading technology vendors to the standardisation process.

The empirical part of the research was carried out using an email questionnaire followed up by semi-structured interviews with a number of key experts.

Three categories of people were approached.

- Experts who had participated in the ISO standardisation work studied, including experts who are currently active and those who have dropped out from the standards committee.

- Decision makers in software companies which implement standards in their products.

- IT-managers from design consultancies, building clients and construction companies.

The email questionnaire was during the autumn of 2005 sent to 27 experts in 12 countries, and 17 responses were received. Of these 7 were also interviewed.

Another option would have been to have addressed a broader spectrum of industry CAD users via a web questionnaire, in line with the broader ITbarometer studies [15]. The response rate to this type of questionnaire can, however, be very low which means that the results are unreliable. This is

\footnotetext{
${ }^{1}$ The writers of this paper have been actively engaged in different stages of national and international CAD layer standard efforts. Bo-Christer Björk was the chairman of the ISO committee during 1993-97. Rob Howard was the UK representative on the committee during that time and had been chairman of the UK standards committee.
} 
because those who answer tend not to be representative of the whole population (they may have a particular interest in the technology). Identifying the right target population can also be very difficult. Thus this alternative was rejected.

\section{The origins of standards for organising building data in CAD system layers}

As soon as CAD systems became widely used in the construction industry and offered facilities for allocating data to layers, users started to devise systems for allocating layers to restrict access to those responsible and, more importantly at that time, for switching off data on hatching or text to make the early CAD systems respond more quickly [16]. At the same time more advanced CAD systems were being used in aerospace and automotive companies and the need to exchange data in structured form led to development of the first standard, IGES, the Initial Graphics Exchange Specification, which eventually became an ANSI standard (ANS Y14.26M-1981) in the US [17]. This was examined by CAD users and vendors in Europe and found to be less suitable for buildings with their many simply shaped components compared with the fewer complex forms used in planes and cars. 


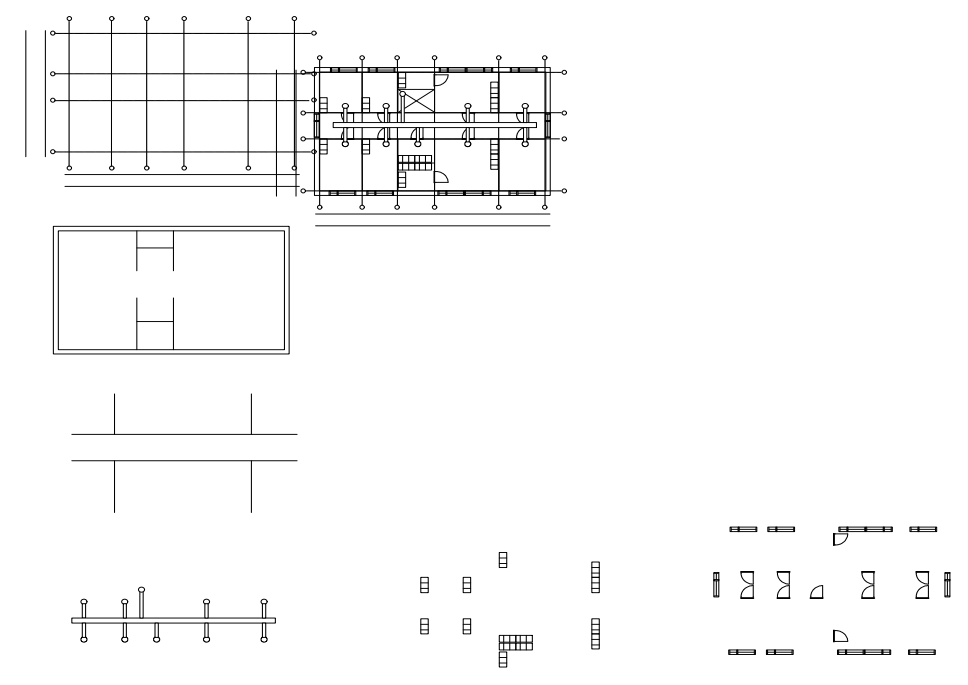

Figure 1. CAD layering divides the total information in a drawing into a number of transparent sheets, which are switched on and off, for screen viewing or printing.

CAD vendors started to issue recommendations for the use of layers but user requirements were often very specific to their projects and to the number of project team members using CAD. During the 1980s there were many incompatible CAD systems and the priority was just to get data translated between them. In the UK the National Economic Development Office set up a working party on CAD data exchange to address this problem. A survey of the use of different CAD systems in construction was carried out in 1988 [18]. The probability of the whole design team on a project having CAD systems that could exchange data was less than $1 \%$ for all firms but $74 \%$ for larger architects and engineers.

When it was possible to exchange data using direct translators or via the IGES graphics standard, it then became important for the data to be structured in a form agreed by all members of the design team. In the UK this led to the formation of a British Standards Committee to add to existing drawing standards one on producing drawings by computer. When the usage of layering facilities was studied, an enormous diversity was found in the ways in which they were being allocated. No common approach could be found although some applied the $\mathrm{CI} / \mathrm{SfB}$ system used for classifying other building data. 
It was decided to focus the standard produced, BS 1192 Part 5 (BS 1990), on the common elements of CAD systems, how they produced drawings from models, guidelines for allocating layers and advice on managing the data exchange process [19]. This aroused interest in other countries where work was starting on similar national standards. BS 1192 Part 5 appeared to meet a need and was much quoted in the UK and used in very diverse ways. It was a very modest proposal but had the merit of being applicable by all CAD users. The standard recommended for building elements the use of either the $\mathrm{CI} / \mathrm{SfB}$ classification or Common Arrangement which is more suitable for use at the construction stage. It was also recommended that a minimum number of layers, manageable by all those involved, should be used rather than the complex structures being offered by CAD vendors. The text of the standard was sold by the British Standards Institution as an expensive publication. Its use was greatly helped by Autodesk distributing a complete $\mathrm{SfB}$ layer table free, but this led to many thinking it was a proprietary standard from one CAD vendor.

In the US the CAD Layer Guidelines published by the American Institute of Architects in 1990 was the first national drawing standard [20]. This was specifically designed for data in CAD systems and a debate took place at the ASCE conference in New York in 1990 in which the UK view that CAD layers should use existing classification systems was strongly presented.

In Sweden the need for a standard for layer structures was recognised around 1990. At that time there were three CAD applications sharing the AEC CAD market. The oldest was MEDUSA BYGG, a construction-specific application built on top of the minicomputer-based MEDUSA system. There were also two competing vendors offering AutoCAD-based systems, POINT and ArCAD. The installed base of the AutoCAD systems vastly outnumbered Medusa.

All three systems spanned the various disciplines involved in building design (architecture, structural, interior, electrical, HVAC and landscape). Also, they all used layer structures designed to facilitate the various production drawing types specified in Swedish standards and recommendations, but layer names were built in significantly different ways. Medusa Bygg could use a total of 1024 numbered layers, and each technical discipline (corresponding to an application software module) had a separate range reserved within that limit. As there was a limited number of layers, the whole structure was fixed and identical for different projects. Since POINT was based on AutoCAD, layer names were not limited to numbers, but could also contain letters. Although this system also used a series of numbers, there was a letter for the discipline added in front of a three digit number. The number basically signified building element and was sometimes followed by a trailing letter to indicate presentation - such as 
dimensions - or other properties of the layer. ArCAD used the potential of AutoCAD in the sense that layer names were composed of letters, and thus could be easily read. Layer names consisted of discipline letter and description, such as A-WALL, A-OPENING, E-LIGHTING or E-DIMENSIONS. The number of layers was limited to what was needed for common drawing types, but there was a software tool to manage project or company specific additional layers, for selecting and tying them to functions of the application.

With building teams working more internationally in the 1990s it was obvious that there should be an ISO standard for CAD layers and a working group was set up within TC10 Technical Product Documentation SC8 in order to define the standard. This looked at a wider area including layer naming and referred to other means of organising CAD data by reference files and object models. The work of the working group received input from several countries, with particularly strong input from the UK and Sweden, where there already were ongoing developments as described above.

The layer structures and names proposed in the ISO work were more specific and allowed for building elements to be classified by national systems. ISO 13567 Parts 1 and 2 introduced a faceted code for each layer with some mandatory fields and some optional ones to incorporate all the requirements of the different countries represented. The committee tried to strike a balance between different national requirements to reach a compromise which would be easily adaptable to national standards, while at the same time making possible the building of generic layer management applications and easy translations between different national and company-specific applications. The coding system is illustrated in Fig 2.

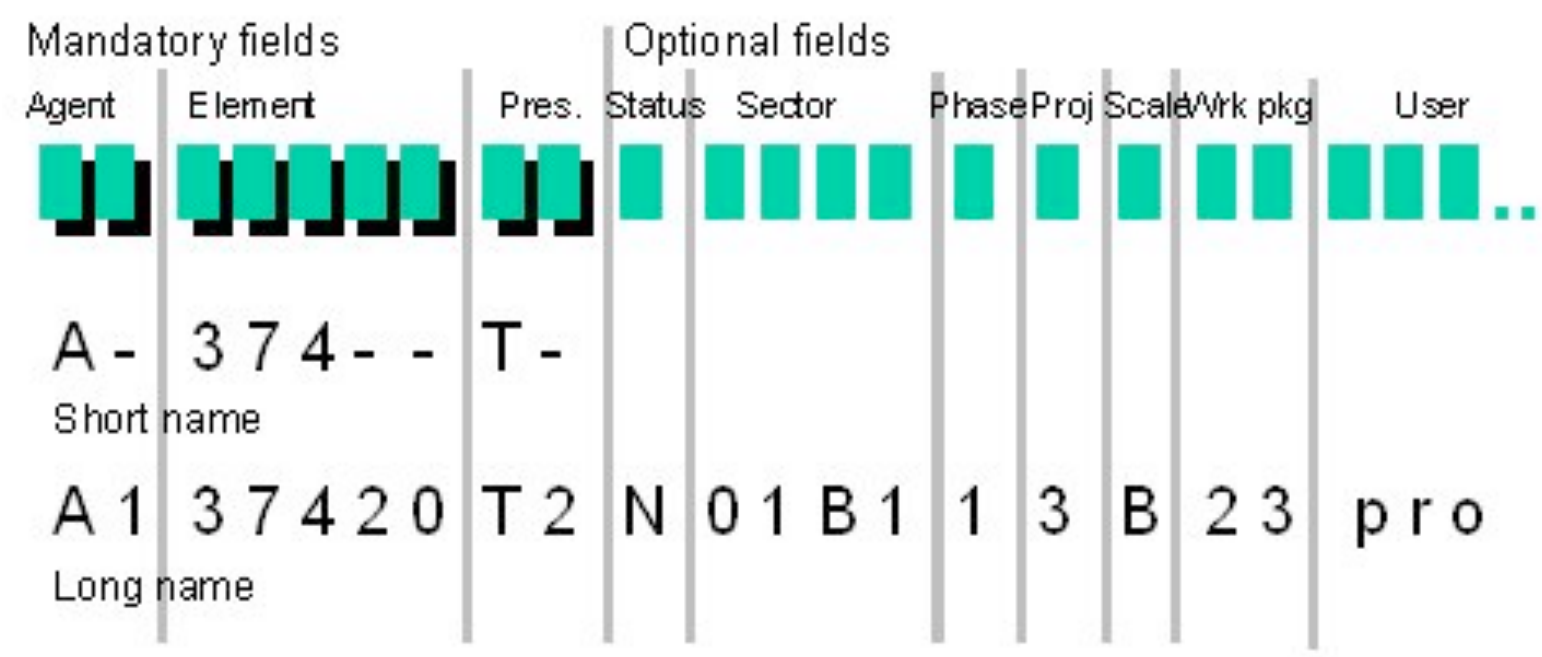


Figure 2. The structure of the ISO 13567 standard with three mandatory fields and some optional ones, leaving the values of fields for national and company specific definition.

International standards are usually given little promotion by ISO itself, since the organisation assumes that the companies and organisations participating in the development of a standard also promote it. This was also the case for ISO 13567 which allowed for national implementations as subsets of the whole.

\section{Survey results}

The questions in the survey dealt with the efficiency of the standards process, its timeliness and industry take up.

\section{Demographics and standards awareness}

The countries of the respondents were: seven from the UK, three from Finland, two from Germany and one each from: Singapore, Japan, Denmark, Sweden and the USA. The roles related to standards of the respondents were, in order of popularity: standards committee member (10), CAD/IT manager (6), research (4), CAD user (4), CAD developer (4), professional body (2), Government (1). The professions of respondents were IT (10), architect (5), contractor (1), engineer (3), academic (1). Some respondents had multiple roles or professions, which means that choices sum to more than the number of respondents.

Among the seventeen experts who responded to the semi-structured questions, there was wide awareness of ISO 13567 (10/17). More of those responding had been involved in its development (6) than application (2). Even more were aware of the Industry Foundation Classes (15/17) but knew of little use of these. Since these are well networked experts the conclusions to be drawn are that there has been much more talk and promotion of the IFCs in recent years than the ISO layer standard, which is almost 10 years old. The respondents' knowledge of national CAD layer standards, which is partly based on ISO 13567, reflected the country of origin of the respondents. Among standards mentioned were BS 1192-5 (UK), Bygghandlingar 90 (Sweden), RT 15-10624 (Finland), CP83 (Singapore).

\section{Functionality and timing of the standard}

Respondents were asked whether the technical specification of the ISO standard is adequate for the problems it aims to solve eg: coordinating data exchange, managing responsibility, national subsets and guidance to users. 5 respondents agreed fully, 7 agreed to some extent and 2 disagreed to some extent. None were in total disagreement. The main reasons for not fully agreeing were that it is not fully object-oriented or that national guidelines were already in place. Most respondents thought ISO 13567 was suitable for general CAD users (8) and 
compatible with most CAD systems (8). A few felt it was difficult to implement (4) and too complex for users (4), or too basic to improve the process (3).

The time the standard was published in 1998 was generally felt to be right or a bit too late. For instance in Denmark and Germany national guidelines already existed. It was also felt that the ISO standard was not well promoted. One respondent thought CAD layer usage too multi-faceted for a single standard.

\section{Maturity of the technology for implementing standards}

The CAD systems used by the respondents were quite diverse but included: AutoCAD, ADT, Revit, AllPlan, ArcInfo, Microstation, Triforma, Vectorworks, SIA CAD, SketchUp, SMC, MagiCAD, Tekla, ArchiCAD. These systems were regarded by almost all as capable of applying CAD layer standards (14) and by many as suitable for IFCs (10). Partner firms were more capable of applying layers (11) than IFCs (5).

\section{National CAD layer standards based on ISO 13567}

There are several national implementations of ISO 13567 and other informal standards make reference to official ones. Most of these used all the mandatory fields in ISO 13567: Agent, Element, Presentation. The optional fields included were: Status, Sector, Phase, Project, Scale, Work package, User defined. In some cases extra characters and sub elements had been added.

The level of usage in each country of these national standards was generally high (9) or medium (4). In Singapore a survey in 2003 had indicated 37\% usage of CP 83. In the US non-scientific sampling of government and education indicated 20-30\% use. In Denmark the Ibb CAD layer guidelines were being used by over $30 \%$.

\section{Who should define standards?}

Most felt that standards should be defined nationally (12) and internationally (10). Also involved should be professional bodies (6), regional standards bodies (4) and unofficial groups (4), but not software vendors.

\section{How should national standards work be resourced/funded}

Currently resources come from public sources, user organisations, software vendors and end users. Respondents felt that ideally most should be from public sources (10), user organisations (10) and software vendors (8) but also end users (6) and building owners (1).

\section{Who should be responsible for the promotion of standards}

This is currently mostly done by standards bodies and professional and user associations, but also software vendors and their user groups and clients/project 
teams. Ideally promotion should be carried out by professional and user associations (12) and standards bodies (8) plus software vendors (7) and clients/project teams (8) and also professional marketing organisations (5).

\section{Interview results}

Seven of the respondents were interviewed face-to-face or by telephone in order to go deeper into some of the questions already included in the questionnaire. In addition to providing general comments this also clarified the situation concerning CAD layer standards in different countries. 


\section{GENERAL ISSUES}

\section{Is the formal standards route the best to reflect user requirements and ensure use?}

A major criticism of ISO 13567 was that it was not fully object-oriented and not well promoted. This raises further questions about the role of standards and how wider usage can be encouraged. Opinions differed on the need for formal standards since they often take too long, but guidelines such as AEC(UK) [21] and Avanti [22] in the UK are often too prescriptive and reflect methods used by a few leading CAD users. They do help to promote use of the official standards, however.

Should standards reflect current CAD use or promote more advanced uses? According to the respondents there is a need for standards of both types - basic ones that can be used by all and more proactive ones. For example in the US the BIM Capability Maturity Model [23] is being developed to cover representation from paper-based to full object models. ISO 10303-202 covers both 2D and 3D data exchange. CAD layers should not be necessary with object models, which allow organisation and selection of objects by many different attributes.

\section{What role should user groups and CAD vendors play in promotion?}

ISO 13567 was generally regarded as technically adequate to meet its objectives and compatible with most CAD systems, but some difficulty was found in implementation and some felt it was too basic to improve the process. The national standards developed from it all used all the mandatory fields for layer naming but few of the optional fields. The AutoCAD user groups in the UK wanted to redo the British standard to reflect the peculiarities of AutoCAD layering and the experience of large practices. It is important to get users' needs but user groups and vendors tend to build proprietary factors into standards.

\section{How can standards be resourced and promoted without compromising impartiality?}

A variety of CAD systems were used by the companies of those responding, including the most common ones. Almost all the systems were capable of applying the standard and some could also apply IFCs. The lead consultants responding were generally more capable of using these than their partner firms. One suggestion was that vendor support could be recognised by putting the logos of a variety of firms on the documentation. The UK government has put resources into ad hoc guidelines as well as standards but fails to follow them up with promotion.

\section{What role should clients and project extranets play in encouraging use of standards?}


Further research and development was on-going or felt to be needed on: reasons for use, or non-use, of standards, design object libraries, provision of business objects, toolkits for architects, help for product manufacturers to develop objects, promotion and education. Project extranets are now widely used and some structure can be built into them such as the seed files necessary to share reference files in Microstation. Print shops have a major role in supplying extranets and could help promote standards. Clients, such as the British Airports Authority (BAA) in the UK, have helped to develop experience. Project servers with software available to all users of an extranet did not work since all users wanted to control their own software.

\section{If ISO 13567 was revised should the number of fields be reduced and should the mandatory fields have greater importance, say by the $\mathrm{EU}$ making it a CEN standard?}

ISO 13567 is already numbered as a CEN standard but there has been no input from EU committees. It was felt that the EU would not enforce the standard and might slow up development. Resources for standards development came nominally from public bodies such as ISO and national standards bodies that service the drafting and publication. They also come from the voluntary input of altruistic individuals or companies with an interest in the results. Inevitably there are insufficient funds for research and development of more complex standards, such as the IFCs, and these often depend on academic work. Promotion of standards is under-resourced and relies upon the official status of an ISO or national standard. There is obviously a role for software vendors and construction clients.

One technical suggestion was for the layer structure to have two levels - one a national one with natural language interface and the second a more cryptic international standard for transfer between applications. In the US the AIA CAD Layer Guidelines were incorporated into the US National CAD Standard [24] in 1999. This includes all the fields in ISO 13567 but the NCS is not formally linked to it and only mandatory fields are widely used.

There will also be a continuing need for layers in developing countries.

\section{How soon will building data be generally shared as models and will layer standards have any relevance at that stage?}

Most experience of applying ISO 13567 is through national implementations using local classification systems. The needs for presentation of CAD data have not been solved by IFCs and layers are still relevant. One view was that they will still be useful for the next ten years. Education of users is essential for encouraging greater use of 3D and therefore of more advanced models. Large clients such as the US military, Danish government, BAA, who build British 
airports, and Senaatti, who commission Finnish academic buildings, will have a major influence on this development.

\section{Current state of CAD layer standards in different countries}

USA - In the US the latest version of NCS is 3.1 released in 2005 and version 4.0 is expected in late 2007. The Uniform Drawing System Modules published by the Construction Specifications Institute have been incorporated into the NCS. Their Overall Construction Classification System is designed for use with layers or with the ISO work on STEP [25]. Other contributors to the NCS are the National Institute of Building Sciences and the Tri-Service CAD/GIS Technology Center [26].

Denmark - the Digitale Byggeri project [27] is expected to recommend government departments to require 3D models from 2007. There should be a new layering standard - 3D Arbeits Metode Doc 3 - coming from this project.

Germany - ISO 13567 was not adopted in Germany since several proprietary standards existed. The only formal standard for AEC is STEP AP 225 (Building elements using explicit shape representation ), which was developed by German representatives on the STEP committee, but which has seen very little use. 2DCAD STEP-CDS is recommended by construction industry associations.

UK - BS 1192 Part 5 was updated as a subset of ISO 13567 in 1998 and is still widely used [28]. The committee responsible for it is being reconvened and may recommend another part for object models. Various unofficial guidelines have been proposed but all make reference to ISO 13567. Product manufacturers are interested in standards objects.

One of the leading building clients in the UK is BAA who own and operate the main airports. They are well aware of the importance of standards and have pioneered framework arrangements and partnering contracts while working towards 3D modelling of their buildings. Their 2D/3D Model \& drawing standards are published on the web [29] for their partners to use. Layering is a major element within these and they have adapted BS 1192, as a subset of ISO 13567 , to use their own categories. Their aim is to move towards standard 3D models, and their framework agreements with consultants and contractors last for ten years so that there should be time, over a series of projects, for all their teams to become familiar with their basic standards, such as layers, and move towards more advanced object models. Their Terminal Five project at Heathrow airport is the largest current construction project in Europe and is based on a 3D CAD model in AutoCAD ADT. Before any data is incorporated in the model it 
goes through compliance checks for level of detail, layers, object structure and completeness. The $£ 4.2$ billion project is due for completion in 2008 .

Sweden - Construction Documentation 90 is not a formal standard but includes ISO 13567 and is widely referenced in project documents. FI2002 is the standard for FM information.

Hong Kong -Layer guidelines based on ISO 13567 have been tested, but this has not lead to any national standard.

Finland - a standard was published in 1996 and is about to be revised. The Rakennustieto guideline RT 15-10624 recommends ISO 13567 CAD layers. Major Clients, such as Senaatti for academic buildings, recommend using layer standards. Their experiences are very instructive and are summarized in the following section is, based on the interview with Kari Alatalo.

Senaatti has approximately 800 construction, refurbishing and maintenance projects going on at the same time. The spread of applications used encompasses in practice all the programs on the market. Senaatti has already for several years posted its requirements for the format and structure of CAD-documents on its web pages, as part of the general CAD-guidelines.

Already at the time of creating the CAD guidelines it was clear that it was impossible to impose one particular layer standard. The level of CADknowledge in the industry was so bad. Today it sounds almost amusing that the requirement in the original guidelines was that layers should be used to be able to structure the information. In the latest revision there is a list of things which it should be possible to put on different layers, as a minimum requirement.

The CAD guidelines consist of both requirements and recommendations. The layer standard from the Building Information Foundation (RT) was from the start a recommendation. It was also allowable to use some other standard, to be agreed to in the beginning of the project. Such were for instance certain layer conventions enforced by the CAD-applications, internal layer standards of the participating firms and combinations of these. The key issue was that this agreed layer standard should be then be followed consistently by the project team. Experience has shown that this has not always been the case.

The Senaatti experience thus demonstrated that even the enforcement of a relatively simple standard, such as the ISO 13567 and its national implementation, has been too ambitious a challenge at this stage. It has also showed that the only way to get layer standards implemented is if software vendors support them actively in the applications. 


\section{Conclusions}

This study has focused on well-informed experts who have helped to develop or implement CAD layer standards. It is not representative of a wide sample of the construction industry nor does it cover more than a few countries. In most of the countries from which respondents replied there are national CAD layer standards based on ISO 13567. In some there are also ad hoc guidelines which make reference to ISO 13567. Usage is thought to be not as high as the experts would like and there is inevitably a wish for more advanced standards, such as the object-oriented IFCs, to become generally accepted. Some countries outside Europe such as Singapore, Japan and Hong Kong have implemented similar standards, but there is little indication of this in southern or Eastern Europe. The US pursues several of its own developments and these are likely to be influential on vendors. A few American experts have been involved in the ISO work on CAD layers.

Formal standardisation was generally preferred by the respondents since ad hoc guidelines are often driven by a small number of large companies or by CAD vendors. Involvement of the EU was not expected to help enforce standards and was deemed to slow development down. There was a need for both low level standards, such as CAD layers, which would relate to all CAD users, and for more proactive standards such as the IFCs. However the gulf between these is wide and there is a need to bridge it through intermediate steps such as $3 \mathrm{D} d x f$, STEP ISO 10303-202 or the BIM Capability Maturity Model.

Promotion of standards is vital, and consulting users on their needs rather than letting these be expressed by user groups or CAD vendors, is also important. Resources provided by those with a commercial interest and by government are necessary, and their input could be recognised by putting their logos on documentation. Clients can have great influence on their project teams applying standards. Extranets could also be a means of building standards into project documents and their suppliers could be approached to discuss this.

Getting information about ISO 13567 has not always been easy. ISO itself and the national standardisation bodies get revenue from the sales of the standards' text, which are not openly and freely available on the net, but have to be purchased. Thus surprisingly a Google search with the term "ISO 13567" results in the following:

- The No 1 item is a scientific article written about the standard and its technical structure [2]. 
- The third and fourth items are catalogue listings on ISOs homepages to the first two parts of the standard [4]. One can order PDFs of the standard text via these.

- The eighth item is the link to a rather detailed technical description of the standard, which is freely available in the Wikipedia web dictionary [30].

The experts contributing to this study were disappointed at the low level of use of the CAD layer standards and frustrated by the lack of take up of object models. There are signs of a move towards 3D models of various types with education essential for spreading experience, and building product object libraries helping the creation of standards models of buildings.

Further work on ISO 13567 is not currently planned within ISO but national implementations are being maintained and referenced in documentation guidelines. CAD layers address the needs of the vast majority of CAD users still working in 2D and will continue to be appropriate for developing countries for many years yet. Object models have many more ways of organising data but layers are likely to continue to be one of these.

\section{Acknowledgements}

This work has been funded through a grant of the Academy of Finland to Prof. Bo-Christer Björk and a Senior Fellowship from the Hanken Foundation to Rob Howard. The contribution of all the experts who participated in the study is warmly acknowledged. 


\section{References}

[1] Amor R, Betts M, Coetzee G and Sexton M (2002) Information Technology for Construction: Recent Work and Future Directions, ITcon Vol. 7, pg. 245-258, http://www.itcon.org/2002/16

[2] Björk, Bo-Christer, 1999

Information Technology in Construction - domain definition and research issues International Journal for Computer Integrated Design and Construction, Vol 1, Issue 1, 1999, pp. 3-16

[3] Howard, R. Computing in construction - pioneers and the future, Butterworth Heinemann, 1996

[4] ISO 13567-1:1998 Technical product documentation -- Organization and naming of layers for CAD -- Part 1: Overview and principles, ISO 13567-2:1998 Technical product documentation -Organization and naming of layers for CAD -- Part 2: Concepts, format and codes used in construction documentation, ISO/TR 13567-3:1999 Technical product documentation -- Organization and naming of layers for CAD -- Part 3: Application of ISO 13567-1 and ISO 13567-2

[5] Eastman, C. M. Building Product Models - Computer Environments Supporting Design and Construction, CRC Press, Boca Raton, Florida1999.

[6] IAI, International Alliance for Interoperability, homepage, http://www.iai-international.org/

[7] Froese T Future directions for IFC-based interoperability, ITcon Vol. 8, Special Issue IFC - Product models for the AEC arena , pg. 231-246, http://www.itcon.org/2003/17

[8] Ekholm A (2005) ISO 12006-2 AND IFC - Prerequisites for coordination of standards for classification and interoperability pg. 275-289, http://www.itcon.org/2005/19

[9] Björk, Bo-Christer, Löwnertz, Kurt, Kiviniemi, Arto ISO 13567 - The Proposed International Standard for Structuring Layers in Computer Aided Building Design Electronic journal of Information Technology in Construction, ITcon, Vol 2/2 (1997), http://itcon.org/1997/2/

[10] Tse T C, Wong K D (2004) A case study of the ISO 13567 CAD layering standard for authomated quantity measurement in Hong Kong, ITcon Vol. 9, pg. 1-18, http://www.itcon.org/2004/1

[11] Cargill, C. Information Technology Standardization: Theory, Process, and Organizations, Digital Press, Bedford, MA, 1989

[12] de-Vries, H. J. Standardization-a new discipline? Proceedings from the 2nd IEEE Conference on Standardization and Innovation in Information Technology. Proceedings. IEEE, Piscataway, NJ, USA, pp. 91-105, 2001

[13] Fomin, V. Keil, T. Standardization: bridging the gap between economic and social theory, Proceedings of the twenty first international conference on Information systems, Association for information systems, Atlanta, Georgia, Pp: 206 - 217, 2000 
[14] Shapiro, C and Varian, H. (1999)

Information Rules, A Strategic Guide to the Networked Economy

Harvard Business School Press, Boston, Massachusetts

[15] Samuelson O (2002) IT-Barometer 2000 - The Use of IT in the Nordic Construction Industry, ITcon Vol. 7, pg. 1-26, http://www.itcon.org/2002/1

[16] Stitt, F. A. Systems Graphics, McGraw-Hill, New York, 1984

[17] American National Standards Institution. ANS Y14.26M-1981. International Graphics Exchange Standard.

[18] Howard, R. 1988 CAD use by size of firm and future needs for data exchange. NEDO Working Party on CAD data and IT exchange in the building industry. NEDO, UK.

[19] Howard, R. Modelling buildings and classifying data in CAD systems. In Conceptual modelling of buildings, CIB proceedings 126, eds Christiansson, P and Karlsson, H. 1988.

[20] American Institute of Architects. AIA CAD Layer Guidelines. Draft publication. Chapter 9.

[21] AEC UK: CAD Standards for Advanced Layer Naming v2.4, CAD Standards for Basic Layer Naming v2.4, www.aec-uk.org/

[22] Avanti, ICT enable collaborative working, www.avanti-construction.org 23 March 2005

[23] National BIM Standard Project Committee. NIBS Facility Information Council. BIM Capability Maturity Model. Draft 2006

[24] US National CAD Standards. Draft of private communication to the author from Won S Jang, editorial assistant to Prof M J Skibniewski, editor of automation in Construction.

[25] NIBS. CAD Standard Version 3.1. 2005. www.nationalcadstandard.org/ 5 January 2006

[26] Hall \& Green. Architects Guide to the US National CAD Standard. 2006

[27] Digitale Byggeri. www.detdigitalebyggeri.dk/

[28] British Standards Institution. BS 1192 - 5. 1990, revised 1998. Construction drawing practice - guide for structuring and exchange of CAD data.

[29] BAA. 2D/3D Model and Drawing CAD Standards. 2003. www.baa.com, 5 January 2006

[30] ISO 13567. http://en.wikipedia.org/wiki/ISO_13567 